\title{
Malignant salivary gland tumors: A short review
}

\author{
Ricardo Hsieh* \\ Institute of Tropical Medicine, University of São Paulo, Brazil
}

\begin{abstract}
Both major and minor salivary glands can develop benign or malignant tumors. Malignant Salivary Gland Tumors (MSGT) are very rare and they haves a great pathological diversity.

It is known that their tumorigenesis is a very complex and dynamic process, which is divided into three stages: initiation, progression and metastasis. In addition to grade and tumor stage, both the presence of lymph node and distant metastases are considered primary factors associated with disease prognosis, recurrence and survival in MSGT patients.
\end{abstract}

The etiopathogenesis and biological behavior of these particular tumors remain unclear, thus, further new investigations involving protein and molecular analysis are needed to have a better understanding of these cancers.

\section{Introduction}

Salivary glands are epithelial tissues specialized in the production and secretion of saliva, which lubricates the mouth and throat. Moreover, it contains enzymes that initiate food digestion process, and also contains antibodies and other substances that help preventing infections.

There are two types of salivary glands: the major and the minor. There is a pair of major salivary glands on each side of the face: the parotid, the submandibular and the sublingual. The minor salivary glands are very small structures, not visible to the human eye, and are dispersed throughout the mucosa.

Both major and minor salivary glands can develop benign or malignant tumors. Malignant Salivary Gland Tumors (MSGT) are very rare and they haves a great pathological diversity. According to World Health Organization (WHO), they comprise around 21-24 histological subtypes [1,2]. It is known that their tumorigenesis is a very complex and dynamic process, which is divided into three stages: initiation, progression and metastasis. In addition to the grade and tumor stage, both the presence of lymph node and distant metastases are considered primary factors associated with disease prognosis, recurrence and survival in MSGT patients [3-5].

The regional neck lymph node and distant metastases are considered as main causes of the treatment failure and/or death in patients with MSGT, thus these metastases still represent a major challenge for both pathologists and clinicians in the diagnosis and treatment $[4,6]$.

\section{Literature review}

\section{Epidemiology}

Malignant Salivary Gland Tumors (MSGT) are very rare diseases (the incidence is $0.5-2$ per 100,000 ), accounting up to $20 \%$ of all salivary gland neoplasms, representing about $1-7 \%$ of head and neck cancers and accounting for $0.3 \%$ of all human cancers [1,2,7-11].

The incidence is reported between 40 and 60 years old, and it is slightly higher in men than in women $[8,12]$. Although the parotid gland is the most common site for salivary neoplasm, only $25 \%$ of parotid tumors are malignant compared to $40 \%, 50 \%$ and $90 \%$ of neoplasms reported as malignant among submandibular, minor salivary gland tumors and sublingual glands cancer, respectively $[9,13]$.

\section{Classification}

According to the New Classification of Head and Neck tumors by World Health Organization in 2017, MSGT can be classified in around 20 subtypes. There are some studies involving the most common among them (Table 1).

\section{Risk factors}

The main causes of MSGT are still not clear. Although the findings in the literature remain controversial, there are some risk factors that are related to the etiology, such as: radiation exposure, tobacco and alcohol consumption; exposure to chemical products or hair dye exposure; diets with low in vegetables and high in animal's fat; history of prior cancer associated to UV radiation, immunosuppression and Epstein-Barr and HPV viruses [12,15,16].

\section{Metastasis}

The histological type and grade are strongly related to poor prognoses, and also are relevant predictors of regional lymph nodes and distant sites metastasis, and these are very significant prognostic indicators of survival after the final definitive treatment [17].

According to Aro et al, 2018, in patients with oral cavity, laryngeal hypopharyngeal cancers, the quantity of pathologically positive lymph

*Correspondence to: Ricardo Hsieh, DDS, PhD, Avenida Doutor Enéas de Carvalho Aguiar, NO. 500, Prédio II, 2o Andar, São Paulo, SP, Brazil - CEP: 05403-000, Tel. +551130617064/+5511966369564, E-mail: r.hsieh@usp.br

Key words: salivary gland, malignant tumor, primary, metastasis, immunohistochemistry, molecular markers

Received: December 25, 2020; Accepted: January 18, 2021; Published: January 20,2021 
nodes (LNs) has been shown to strongly correlate with survival, revealing a better metric prognosis than classic LN factors described at American Joint Committee on Cancer (AJCC) eighth edition pathological node staging system. Thus, they proposed a Novel Salivary Gland Cancer Lymph Node Staging System (Table 2).

Later, Elhusseiny et al., 2019 suggested to include examined (dissected) LNs; positive LNs counts; LNs ration into the staging system [13].

In the literature, we can find neck lymph node positivity ranging from $14-50 \%$ and occur more frequently in high-grade and advanced T-stage tumors and/or in presence of extracapsular extension and/or facial paralysis irrespective of histology, associating to the decrease in survival. However, among patients with major salivary gland cancer, positive nodal disease confer a greater than $50 \%[8,12,18]$.

In a study of 160 patients with MSGT, $13 \%$ of the patients presented clinically apparent cervical lymph node metastasis, and the overall incidence of pathologically confirmed lymph node metastasis was 53\% [19]. Later, Elhusseiny et al., 2019 evaluated 5446 patients with MSGT, which $65.28 \%$ were $>50$ years old and $37.4 \%$ in grade III and IV. Parotid gland was the most frequent site 84.61. According to their results, the mean of the examined (dissected) LNs; negative LNs; positive LNs and LNs ratio was $12.46 \% ; 10.27 \% ; 2.38$ and $16.57 \%$, respectively [13].

The mucinous adenocarcinomas (MAC) is a very rare disease, accounting only $0.1 \%$ of all salivary gland tumor, however, the majority salivary MAC present cervical nodal metastasis in $63 \%$ of cases [20].

On the other hand, Distant Metastasis (DM) depends on: primary tumor site; tumor stage and grade; perineural spread; cervical nodal status and genomic signatures. The most common sites are: lung; bone; liver and brain $[21,22]$.

In a study of 60 patients diagnosed as malignant tumor of salivary gland, distant metastases were shown in 52\%, involving lung, followed by liver and vertebrae [23]. Shi et al., (2018) evaluated 255 patients with major salivary gland cancer, which $67.1 \%$ had regional lymph node. Distant metastasis was found in lung (52.9\%); bone 42.7\%; distant lymph nodes (29.4\%) and followed by liver and brain [24]. Recently, a study of a cohort of 884 patients treated for salivary gland carcinoma,

Table 1. 2017 WHO New Classification of Head and Neck tumors and International Classification of Diseases for Oncology (ICD-O)'[12,14]

\begin{tabular}{|c|c|}
\hline Classification & ICD-O \\
\hline Mucoepidermoid carcinoma & $8430 / 3$ \\
\hline Adenoid cystic carcinoma & $8200 / 3$ \\
\hline Acinic cell carcinoma & $8550 / 3$ \\
\hline Polymorphous adenocarcinoma & $8525 / 3$ \\
\hline Clear cell carcinoma & $8310 / 3$ \\
\hline Basal cell adenocarcinoma & $8147 / 3$ \\
\hline Intraductal carcinoma & $8500 / 2$ \\
\hline Adenocarcinoma, NOS & $8140 / 3$ \\
\hline Salivary duct carcinoma & $8500 / 3$ \\
\hline Myoepithelial carcinoma & $8982 / 3$ \\
\hline Epithelial-myoepithelial carcinoma & $8562 / 3$ \\
\hline Carcinoma ex pleomorphic adenoma & $8941 / 3$ \\
\hline Secretory carcinoma & $8502 / 3$ \\
\hline Sebaceous adenocarcinoma & $8410 / 3$ \\
\hline Carcinosarcoma & $8980 / 3$ \\
\hline $\begin{array}{l}\text { Poorly differentiated carcinoma: } \\
\text { Neuroendocrine and non- neuroendocrine undifferentiated carcinoma } \\
\text { Large cell neuroendocrine carcinoma } \\
\text { Small cell neuroendocrine carcinoma }\end{array}$ & $\begin{array}{l}8020 / 3 \\
8012 / 3 \\
8041 / 3\end{array}$ \\
\hline Lymphoepithelial carcinoma & $8082 / 3$ \\
\hline Squamous cell carcinoma & $8070 / 3$ \\
\hline Oncocytic carcinoma & $8290 / 3$ \\
\hline Sialoblastoma & $8974 / 1$ \\
\hline
\end{tabular}

Table 2. Comparing the Novel Proposed Nodal Staging System to American Joint Committee on Cancer (AJCC) $8^{\text {th }}$ Edition Nodal Staging System. (+) indicates positive; (-) indicates negative; ENE indicates extranodal extension; OS overall survival. (adapted from Aro et al., 2018)[5]

\begin{tabular}{|c|c|c|c|c|c|}
\hline \multicolumn{3}{|c|}{ 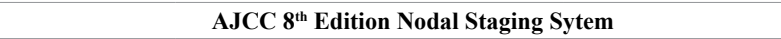 } & \multicolumn{3}{|c|}{ Proposed Nodal Staging System } \\
\hline N-Category & Criteria & 3 years OS & N-Category & Criteria & 3 years OS \\
\hline No & $0 \mathrm{LN}+$ & $89.1 \%$ & No & $0 \mathrm{LN}+$ & $89.1 \%$ \\
\hline N1 & 1 ipsilateral $\mathrm{LN}+, \leq 3 \mathrm{~cm}$ and $\mathrm{ENE}(-)$ & $76.3 \%$ & N1 & $1-2 \mathrm{LN}+$ & $72.1 \%$ \\
\hline $\mathrm{N} 2 \mathrm{a}$ & $\begin{array}{c}1 \text { ipsilateral or contralateral } \mathrm{LN}+, \leq \\
3 \mathrm{~cm} \text { and } \mathrm{ENE}(+) \text { or } 1 \text { ipsilateral } \mathrm{LN}+ \\
3-6 \mathrm{~cm} \text { and } \mathrm{ENE}(-)\end{array}$ & $69.0 \%$ & \multirow{3}{*}{$\mathrm{N} 2$} & \multirow{3}{*}{$3-21 \mathrm{LN}+$} & \multirow{3}{*}{$57.3 \%$} \\
\hline $\mathrm{N} 2 \mathrm{~b}$ & $>1$ ipsilateral $\mathrm{LN}+, \leq 6 \mathrm{~cm}$ and $\mathrm{ENE}(-)$ & $59.1 \%$ & & & \\
\hline $\mathrm{N} 2 \mathrm{c}$ & $\begin{array}{l}>1 \text { bilateral or contralateral } \mathrm{LN}+, \leq \\
6 \mathrm{~cm} \text { and ENE(-) }\end{array}$ & $62.9 \%$ & & & \\
\hline $\mathrm{N} 3 \mathrm{a}$ & $>1 \mathrm{LN}+,>6 \mathrm{~cm}$ and $\operatorname{ENE}(-)$ & $67.7 \%$ & \multirow[b]{2}{*}{ N3 } & \multirow[b]{2}{*}{$\geq 22 \mathrm{LN}+$} & \multirow[b]{2}{*}{$23.5 \%$} \\
\hline $\mathrm{N} 3 \mathrm{~b}$ & $\begin{array}{l}1 \text { ipsilateral } \mathrm{LN}+,>3 \mathrm{~cm} \text { and } \mathrm{ENE}(- \\
\text { ); or }>1 \text { ipsilateral, contralateral or } \\
\text { bilateral } \mathrm{LN}+\text {, any } \mathrm{ENE}(+)\end{array}$ & 50.7 & & & \\
\hline
\end{tabular}


12 had DM at the initial presentation, and 137 presented DM during follow-up. The most common site was lung, followed by liver, bone and axillary lymph node [6].

Adenoid Cystic Carcinoma (ACCa) is one of the two most frequent salivary gland malignancy, accounting for $7.5 \%$ of all salivary gland epithelial cancers and $4 \%$ of all salivary gland tumors. It is characterized by relentless growth and variable recurrence and metastasis rates. Histological feature is composed of epithelial and myoepithelial cells arranged in tubular, cribriform and/or solid patterns, correlating with tumor grade. Classically, the predominance of solid areas and presence of perineural invasion in the tumor, clinical factors (older age), increased tumor size and metastasis, have been used as prognostic factors [25,26]. Lee et al., 2012 observed cervical lymph node in 13\% among 48 ACCa cases [27]. Brazão-Silva et al., 2013 studies 35 ACCa cases, among them, 14 (28.6\%) showed metastases: localized/regional spread in $4.1 \%$; exclusively distant organs (lung, vertebra and kidney) in $16.3 \%$; regional lymph node and distant metastases (lung, liver, vertebra and iliac bone) in $8.2 \%$.(26) A retrospective cohort from a large population cancer database identified 720 patients with ACCa, among them 17.3 showed nodal metastasis and 17.4 showed distant metastasis [28].

The Malignant Mixed Tumor is a very rare entity originated from salivary glands, which has two different types: carcinoma ex pleomorphic adenoma and carcinosarcoma. It accounts for between 3 - $12 \%$ of all MSGT. The most common sites of metastases are regional LNs, lungs, bones and abdominal organs [29,30].

Salivary duct carcinoma (SDC) is a very rare disease, usually affects middle-age men and is often located in parotid gland. It is characterized by a high rate of nodal and distant metastases, resulting in bad prognosis and limited overall survival. Boon et al., 2018 evaluated 177 patients with SDC, and they observed the most frequent metastasis sites were: pulmonary (54\%); bone (46\%); lymph nodes (42\%) and brain (18\%) [31].

The Clear-cell carcinoma is very uncommon tumor involving salivary glands. The incidence is 0.011 per 100,000 and accounting for $<5 \%$ of all salivary gland cancers. Lymph node positivity rates of up to $14 \%$, while distant metastases rate up to $3.3 \%$ of cases. And it was reported a rare cutaneous metastasis case in 2020 [32].

\section{Molecular markers}

The diagnosis for MSGT should be based primarily on the morphologic features and with support of immunohistochemistry. Additionally, molecular analysis of MSGT should reveal genetic alteration, which could find predictive biomarkers and new therapeutic therapies for salivary gland tumors.

A study comparing the immunohistochemical characteristics between benign and malignant major salivary gland tumors, they evaluated some myoepithelial and epithelial immunohistochemical markers (SMA, smooth muscle actin, calponin, S100, CD10, GFAP, p63, GCDFP15, GLUT1, 34ßE12, CK14, CK19, CD117, and galectin-3) in 83 patients. Their results showed that GFAP, S100, CK14, p63, and CK5/6 expressions were significantly lower among malignant neoplasm, while SMA and calponin did not showed significant difference between benign and malignant tumors. But, CK19 expression was significantly higher in malignant diseases. Interestingly, CD117 expression favored Adenoid Cystic Carcinoma; 34ßE12 expression favored mucoepidermoid carcinoma and GCDFP15 favored Salivary Duct Carcinoma and Acinic Cell Carcinoma, while GFAP expression favored in pleomorphic adenoma [33].
Kiyoshima et al., (2001) analyzed P53 protein expression in 17 Adenoid Cystic Carcinoma (ACC) and 27 Mucoepidermoid Carcinoma (MEC) in salivary glands by IHC and p53 tumor suppressor gene alteration by PCR/SSCP. The genetic alterations were detected in $17.6 \%$ of ACC and $14.8 \%$ of MEC. The p53 immunostaining ratio ranged from 0 to $78 \%$ in ACC (mean $=8.2 \pm 20.4 \%$ ) and from 0 to $81.7 \%$ in MEC (mean $=19.2 \pm 26.1 \%$ ), generally the expression was lower in ACC than in MEC. The p53 positive expression in MEC correlated to the histological grade. No correlation exists between p53 gene alterations and p53 protein expression among these tumors [34].

The IHC positive findings for Salivary Duct Carcinoma (SDC) comprise: AR, androgen receptor (73-100\%); HER2 (16-83\%); GATA3 (73-100\%); GCDFP-15 (76-100\%); CEA, carcinoembryonic antigen (71-72\%); CK 5/6 (14-76\%); EGFR (12-33\%); p53 (42\%) and average KI-67 labeling index (35-46\%). And there are some genetic alteration reported in SDC, mainly including: TP32; HRAS; BRAF; HER2; PIK3CA; PTEN; AKT1 and ALK. The differential diagnosis between SDC and metastatic carcinoma of breast origin should be the lack of estrogen receptor or progesterone receptor expression [35].

The Osteopontin (OPN) is also expressed in numerous carcinomas, playing a role in the tumorigenesis, invasion and metastasis. The interaction of OPN with alpha $\mathrm{V}$ beta 3 integrin has been associated with increased tumor aggressiveness and metastatic potential. Darling et al., 2005 observed that Pleomorphic Adenoma and polymorphous low grade adenocarcinoma showed higher levels of OPN than normal salivary gland tissue, while Adenoid Cystic Carcinoma displayed only marginally higher OPN expression than normal salivary tissue [36]. In a Japanese study, they evaluated the expression of OPN in 175 patients with primary MSGT. Although all tumors shown OPN positive immunostaining, Adenoid Cystic Carcinoma showed the highest mean sum score (7.3) and higher proportion of carcinomas with high OPN sum score, comparing to mucoepidermoid carcinoma and acinic cell carcinoma. However, the OPN expression did not correlate with known prognostic factors [37].

In an immunohistochemical analysis of c-kit; HER2; IGFR; ER, estrogen receptor; PgR, progesterone receptor; VEGF; c-MET and survivin in 40 MSGT (including 13 ACC, adenoid cystic carcinoma; 12 CXPA, carcinomas ex pleomorphic adenomas; 15 MEC, mucoepidermoid carcinoma). Their results showed that ACC demonstrated significantly higher c-kit (85\%); IGFR (77\%); ER (38\%) expression, on the other hand, CXPA demonstrated significant HER2 (75\%) staining, while MEC showed significant IGFR (77\%) staining. Thus, they suggest that these findings could be target therapy for these subtype of MSGT [38].

In a Chinese study, they analyzed the expression of NOTCH-1 in clinical Salivary Adenoid Cystic Carcinoma (SACC), and their results showed upregulation of NOTCH-1 in SACC tissues compared to normal tissues. Interestingly, this upregulation was further enhanced in SACC tissues with metastasis and recurrence than SACC cases without metastasis. Thus, they suggested that NOTCH-1 plays a key role in SACC cell growth, anti-apoptosis and metastasis, and it should be a potential therapeutic target [39].

The cyclin-dependent kinase subtype 1(Cks1) expression were evaluated in 64 patients with MSGT (including: 13 mucoepidermoid cell carcinoma, 13 adenocarcinoma, 8 squamous cell carcinoma, 9 acinic cell carcinoma, 7 adenoid cystic carcinoma, 5 low-grade polymorphous adenocarcinoma, and 5 undifferentiated/anaplastic cell carcinoma), and the results were compared to p27, S-phase kinase protein 2 (Skp2), 
Ki-67, p53 and TUNEL expressions. Cks1 expression was increased in $47 \%$ of cases and strongly correlated to increased S-phase kinase protein 2 (Skp2), Ki-67, p53 and TUNEL expression, and it was strongly associated with lymph node metastases, poor prognosis and survival [40].

Programmed death-1 ligand-1 (PD-L1) can suppress the immune system and its higher expression has been related with tumor aggressiveness in some cancers. Harada et al., 2018 examined PD-L1 expression in 47 patients with MSGT, and it was detected in $51.1 \%$ of cases. Moreover the PD-L1 immunodetection of tumor cell membranes was significantly associated to stage, recurrence or metastasis after surgery, and patient outcome [41].

Schneider et al. (2016) investigated EGFR protein expression in 43 MSGT, including adenoidcystic carcinoma $(n=23)$, mucoepidermoid carcinoma $(\mathrm{n}=17)$, and adenocarcinoma NOS (not otherwise specified) $(n=3)$ by IHC. The results showed positive EGFR positive immunostaining in $79 \%$ of cases, which were significantly correlated with patient age and lymph node metastasis [42].

Tang et al. (2001) analyzed CKIT and Slug protein expression in 121 ACC patients by IHC. According to their results, CKIT had positive expression in $89.26 \%$ and Slug in $71.90 \%$ of cases. And these expressions were significantly associated with the tumor size, TNM stage, histological pattern, perineural invasion, local reginal recurrence and distant metastasis among all patients [43].

\section{Conclusion}

Further investigations involving protein and molecular analysis are required to understand the etiopathogenesis, progression and metastasis of malignant salivary gland tumors to develop new therapeutic strategies and offer better prognosis and quality of life for all patients.

\section{Statement}

The author declares there is no conflicts of interest.

\section{Reference}

1. Yoo SH, Roh JL, Kim SO (2015) Patterns and treatment of neck metastases in patients with salivary gland cancers. J Surg Oncol 111(8):1000-1006.

2. Jang JY, Choi N, Ko YH (2018) Treatment outcomes in metastatic and localized highgrade salivary gland cancer: High chance of cure with surgery and post-operative radiation in T1-2 N0 high-grade salivary gland cancer. BMC Cancer 18(1):1-12. [Crossref]

3. Maruyama S, Cheng J, Yamazaki M (2010) Metastasis-associated genes in oral squamous cell carcinoma and salivary adenoid cystic carcinoma: a differential DNA chip analysis between metastatic and nonmetastatic cell systems. Cancer Genet Cytogenet 196(1):14-22.

4. Ettl T, Gosau M, Brockhoff G (2014) Predictors of cervical lymph node metastasis in salivary gland cancer. Head Neck 36(4):517-523.

5. Aro K, Ho AS, Luu M (2018) Development of a novel salivary gland cancer lymph node staging system. Cancer 124(15):3171-3180. [Crossref]

6. Mimica X, McGill M, Hay A (2020) Distant metastasis of salivary gland cancer: Incidence, management, and outcomes. Cancer 126(10):2153-2162. [Crossref]

7. Aghajani MJ, Cooper A, Mcguire H, Jeffries T, Saab J, Ismail K (2019) Pembrolizumab for anaplastic thyroid cancer : a case study American Joint Committee on Cancer. Cancer Immunol Immunother.

8. Bhattacharyya NFMP (2002) Nodal Metastasis in Major Salivary Gland Cancer. Arch Orthop Trauma Surg 128:904-908.

9. Gillespie MB, Albergotti WG, Eisele DW (2012) Recurrent Salivary Gland Cancer. 58-70.
10. Jegadeesh N, Liu Y, Prabhu RS (2015) Outcomes and prognostic factors in modern era management of major salivary gland cancer. ORAL Oncol. [Crossref]

11. Wu H, Ren G, Wang L, Zhang C, Chen W, Guo WEI (2012) Expression of podoplanin in salivary gland adenoid cystic carcinoma and its association with distant metastasis and clinical outcomes. 271-274.

12. Guzzo M, Locati LD, Prott FJ, Gatta G, Mcgurk M, Licitra L (2010) Major and minor salivary gland tumors. Crit Rev Oncol / Hematol 74(2):134-148. [Crossref]

13. Mosaad K, Mbbch E, Mbbch FAA (2019) Examined and positive lymph nodes counts and lymph nodes ratio are associated with survival in major salivary gland cancer. 1-11.

14. El-Naggar AK, Chan JKC, Grandis JR, Takata T SP (2017) WHO Classification of Head and Neck Tumours. In: El-Naggar AK, Chan JKC, Grandis JR, Takata T SP, ed. WHO/IARC Classification of Tumours 4th Edition. 4th ed. Lyon: IARC Publication; 159-202.

15. Spitz, Magaret R; Fueter, John J; Goepfert, Helmuth; Newell GR (1990) Salivary Gland Cancer: a case-control Investigation of Risk Factors. Arch Otoralyngol Head Neck Surg 116:1163-1166.

16. Pan SY, De Groh M, Morrison H (2017) A Case-Control Study of Risk Factors for Salivary Gland Cancer in Canada. J Cancer Epidemiol 2017.

17. Almuhaimid TM, Sub W, Jong L (2018) Pre-treatment metabolic tumor volume predicts tumor metastasis and progression in high-grade salivary gland carcinoma. $J$ Cancer Res Clin Oncol 144(12):2485-2493. [Crossref]

18. Korkmaz H, Yoo GH, Du WEI, Hocwald E (2002) Predictors of Nodal Metastasis in Salivary Gland Cancer. 186-189.

19. Stennerd, Eberhard; Kisner, Dilek; Jungehuelsing, Markus; Guntinas-Lichius, Orlando, et al. (2003) High Incidence of Lymph Node Metastasis in Major Salivary Gland Cancer. Arch Otoralyngol Head Neck Surg 129:720-723. [Crossref]

20. Panaccione A, Zhang Y, Mi Y (2017) Chromosomal abnormalities and molecular landscape of metastasizing mucinous salivary adenocarcinoma. Oral Oncol 66:38-45.

21. Bradley PJ (2001) Distant Metastases from Salivary Glands Cancer. OLR 63:233-242.

22. Glazer TA, Shuman G (2016) Distant Metastases and Palliative Care. 78:182-188.

23. Lee S, Ae H, Jin K, Jin H, Kim S, Chang E (2013) Characteristics, management of the neck, and oncological outcomes of malignant minor salivary gland tumours in the oral and sinonasal regions. Br J Oral Maxillofac Surg 51(7):e142-e147. [Crossref]

24. Shi X, Dong F, Wei W, Song K, Huang N, Lu Z (2018) Prognostic significance and optimal candidates of primary tumor resection in major salivary gland carcinoma patients with distant metastases at initial presentation : A population-based study. Oral Oncol 78:87-93. [Crossref]

25. Chen W, Cao G, Yuan X (2015) Notch-1 knockdown suppresses proliferation, migration and metastasis of salivary adenoid cystic carcinoma cells. 1-10.

26. Brazão-Silva MT, Cardoso SV, de Faria PR (2013) Adenoid cystic carcinoma of the salivary gland: a clinicopathological study of 49 cases and of metallothionein expression with regard to tumour behaviour. Histopathology 63(6):802-809. [Crossref]

27. Lee SK, Kwon MS, Lee YS, Choi S, Kim SY, Cho KJ (2012) Prognostic value of expression of molecular markers in adenoid cystic cancer of the salivary glands compared with lymph node metastasis : a retrospective study. World J Surg Oncol 10(1):266-282.[Crossref]

28. Megwalu UC, Sirjani D (2017) Risk of nodal metastasis in major salivary gland adenoid cystic carcinoma.

29. FUJIMURA, Miki;SUGAWARA, Takayuki;Hirobumi, SEKI;OTAWARA, Yasunari;SAKUMA, Tsutomu;NAKANO, Yoshishige;YOSHIMOTO T (1997) Carcinomatous Change in the Cranial Metastasis from a Metastasizing Mixed Tumor of the Salivary Gland. Neural Med Chir 37:546-550.

30. Yildiz OA · ÇÖ· K (2001) Malignant mixed tumor of salivary gland with a solitary metastasis to the tibia. Arch Orthop Trauma Surg 121:294-296.

31. Boon E, Bel M, Boxtel W Van (2014) A clinicopathological study and prognostic factor analysis of 177 salivary duct carcinoma patients from The Netherlands. 1-9. [Crossref]

32. Abou R, Sheeren S, Mohamed Z (2020) Salivary gland hyalinizing clear-cell carcinoma with cutaneous metastasis : A rare and deceptive tumor. J Cutan Pathol 4-7.

33. Kiremitci S (2019) Comparative immunohistochemical characteristics of benign and malignant major salivary gland tumors: A retrospective study. Turkish J Ear Nose Throat 29(1):9-20. 
34. Kiyoshima T, Shima K, Kobayashi I (2001) Expression of p53 tumor suppressor gene in adenoid cystic and mucoepidermoid carcinomas of the salivary glands. Oral Oncol 37(3):315-322. [Crossref]

35. Nakaguro M, Tada Y, Faquin WC, Sadow PM, Wirth LJ, Nagao T (2020) Salivary duct carcinoma: Updates in histology, cytology, molecular biology, and treatment. Cancer Cytopathol 128(10):693-703. [Crossref]

36. Darling MR, Gauthier M, Jackson-Boeters L, Daley TD, Chambers AF, Tuck AB (2006) Osteopontin expression in salivary gland tumours. Oral Oncol 42(4):363-369.

37. Bjrndal K, Larsen SR, Godballe C, Krogdahl A (2011) Osteopontin expression in salivary gland carcinomas. J Oral Pathol Med 40(6):451-455.

38. KAWAMURA Y, KUNIMURA T, OMATSU M, MORI T, SANBE T, MOROHOSH $T$ (2013) Immunohistochemical analysis of various salivary gland carcinomas focusing on the possibility of molecular-targeted and hormonal therapy. Showa Univ J Med Sci 25(1):29-39.
39. Su BH, Qu J, Song M (2014) NOTCH1 signaling contributes to cell growth, antiapoptosis and metastasis in salivary adenoid cystic carcinoma. Oncotarget 5(16):68856895. [Crossref]

40. Nagler RM, Ben-Izhak O, Ostrovsky D, Golz A, Hershko DD (2009) The expression and prognostic significance of Cks1 in salivary cancer. Cancer Invest 27(5):512-520. [Crossref]

41. Harada K, Ferdous T, Ueyama Y (2018) PD-L1 expression in malignant salivary gland tumors. BMC Cancer 18(1):1-6. [Crossref]

42. Schneider T, Strehl A, Linz C (2016) Phosphorylated epidermal growth factor receptor expression and KRAS mutation status in salivary gland carcinomas. Clin Oral Investig 20(3):541-551. [Crossref]

43. Tang Y, Liang X, Zheng M (2010) Expression of c-kit and Slug correlates with invasion and metastasis of salivary adenoid cystic carcinoma. Oral Oncol 46(4):311-316. [Crossref]

Copyright: (C2021 Hsieh R. This is an open-access article distributed under the terms of the Creative Commons Attribution License, which permits unrestricted use, distribution, and reproduction in any medium, provided the original author and source are credited. 